\title{
Hip Hop headz in sex ed: Gender, agency, and styling in New Zealand
}

\author{
B R I A N W. K I N G \\ University of Hong Kong
}

\section{A B S T R A C T}

This study examines Hip Hop styling, gender, and sexual agency in a sex education class. The focus is on the indirect indexing of gender by a femalebodied student through the Hip Hop cultural personas of braggadocio and swagger, providing a rare look at 'mundane' performances of Hip Hop and its relationship to gender. Discourse analysis demonstrates that she used Hip Hop styling to manage ascriptions of sexual agency during a discussion task as she repeatedly recontextualized the telling of a classroom incident. Her language use afforded the trying out of identity meanings and required complex discursive work in relation to constructs such as masculinity, femininity, straight, and lesbian. These processes assisted her to negotiate how sexual agency might fit with her various identifications and identities. Therefore the potential for Hip Hop styling to connect identities with language has implications for both sexuality education and the study of sociolinguistics. (Agency, gender, Hip Hop, performativity, sexuality, social identities, styling)*

\section{N T R O D U C T I O N}

This article contributes to new directions in language research through a focus on styling, social identities, and Hip Hop culture in a classroom in New Zealand. It provides a rare glimpse into the use of Hip Hop Nation Language (HHNL) amongst Hip Hop fans as differentiated from its artists, most specifically in an educational context. It also explores Hip Hop styling in relation to gender and sexual identity, an under-researched area (Williams 2017), and makes an overdue start at examining the use of HHNL in New Zealand as part of translocal Hip Hop expression.

Using data drawn from a discussion about sexuality in a New Zealand classroom, the analysis in this article demonstrates how an individual speaker recontextualized her speech while repeatedly reporting a critical classroom incident to various classmates. In these various retellings she had to manage the process of identification through 'styling' (Coupland 2007) and performativity. The concept of style has been instrumental in critical sociolinguistics in capturing some of the ways that people connect identities with language (Jaffe 2009; Bell 2016), and the analysis here explores that process in detail by keeping an eye to 'the 
transformative potential of the performative' (Kramsch 2012:493). In other words, using the poststructuralist lens of performativity, it focuses on the making and remaking of gendered and sexual identities, agency, and interpersonal contexts to examine how participants 'open up' fixed-identity categories (e.g. man, woman, gay, straight) by playing with possibilities and 'trying out certain identity meanings in the doing' (Harissi, Otsuji, \& Pennycook 2012:540). It is in this process of identification that they are seen to potentially gain from a discussion-oriented approach to sexuality education.

Insights from studies of style have been influential in gender and language in the past two decades, leading to a more frequent focus on gendered linguistic styles in relation to sexuality (Cameron 2005). Thus this article joins other gendered styling studies in sociolinguistics (e.g. Bucholtz 2001, 2009; Zhang 2005; CampbellKibler 2008; Moore \& Podesva 2009), adding to their diversity by revisiting in detail the ways that 'styling', an interactional practice at the heart of discursive social action (Coupland 2007), can be deployed as one part of the management of sexual and gendered social identities as well as individual subjectivities. By focusing on Hip Hop styling in sexuality-education classroom data in a New Zealand context, this study stands to broaden and diversify key insights in this area.

Sociolinguistic studies of the use of HHNL by MCs during live and/or recorded performances of Hip Hop are now proliferating. However, there is still a shortage of studies that examine its use off-stage in what has been called 'mundane' or everyday performances (Cutler 2015) or what Androutsopoulos (2009) has termed the 'third sphere' of Hip Hop, or interaction amongst fans and activists (for notable exceptions see Roth-Gordon 2009; Pichler \& Williams 2016; Ross 2018). Along with calls for third-sphere studies, there have also been calls to look more carefully at the role of Hip Hop pedagogically to see how engagement with its cultural practices might mediate educational processes and support consciousness raising about students' positions in the world (Alim 2011), in this case gendered positions. The sexuality-education classroom environment of the current study is highly suitable for an exploration of the semiotic potential of HHNL in education. Situated in a New Zealand context, with a number of Pasifika participants weaving Hip Hop cultural practices into their projections of identity, stylizations, and/or language play, an ideal opportunity arises to query how these practices might assist them to maximize their learning as they navigate this particular social and institutional context.

\section{STYLING AND HIP HOP LANGUAGE PRACTICE}

\section{Converging practices of stance and style}

Central to the analytical procedures of this study is the sociolinguistic notion of styling and social identities (Coupland 2007). Aligning with Coupland's model, the study adopts a dynamic approach to identity as an active discursive process. In the data analyzed here, the participants are engaged in 'mundane' performances 
(i.e. everyday, not staged), and these are performances in which use of HHNL indexes certain stances directly during interaction. Those stances in turn index gendered personae that the participants speak through; that is, these personae are INDIRECTLY indexed by HHNL and are mediated by stances, carrying interpersonal consequences (Ochs 1992; Jaffe 2009). Indexicality (Silverstein 2003), as deployed in this study, refers to a semiotic process through which associations are made between identities and linguistic and nonlinguistic forms including styles. In the case of gender and sexual identities, these associations take place mostly indirectly as described above - a process in which acts and/or stances are indexed first via forms (e.g. features of HHNL) - and it is the stance or act that then indexes femininity or masculinity in a local context (Ochs 1992). Rigid regulatory frameworks, of school and gender in this case, constitute fundamental frameworks to conform to or depart from, and particular features of style are selected for use rather than a wholesale enactment of a socially salient style (Jaffe 2009). The selection of style features may entail a variety of activities that sit on a cline from ephemeral (e.g. temporary alignment with stances or even fleeting language play) to more enduring processes such as identity projection (Cutler 2015). These performances are also recontextualized when macro-level frames (i.e. sociocultural), meso-level frames (i.e. genre and social role), and micro-level frames (i.e. interpersonal) shift, and this process of constructing context will also be attended to during analysis.

\section{PER F O R M A T I V I T Y, GENDER, A N D A GENCY}

Conversation is important to sexuality education because discussion provides an opportunity for the 'sorting out' of subjectivities (i.e. the discursive formation of the individual subject) in relation to social identities (e.g. man, woman, trans, gay, straight) via performativity in action, as subjectivities are constructed through repeated acts of language (Harissi et al. 2012). During the analysis presented here, the participants are positioned by self, others, and learning materials in ways that mobilize sexual agency, or do not, and therefore agency cannot be separated from their gender and sexual identity practices. Indeed it is these various performances and ascriptions of agency in relation to sexual activity that prompt participants to try out identity meanings as they interact.

\section{Agency}

Agency here refers to a discursive mobilization of a capacity to act (Ahearn 2010) in relation to sexuality. What this means in practice is that the capacity to act on sexual desires, or importantly also to not act on them, is constructed through positioning of interlocutors in conversation via sexual or nonsexual subject positions that are also imbued with a sense of 'actorhood' in relation to sex. These sexually agentive subject positions are ascribed, resisted, aligned to, and performed depending on 
the positioning of subjects in interaction (Thompson 2011; B. King 2014a,b). It is important not to dichotomize structure and agency (Eckert 2012; Bell 2016); rather the focus should be on how participants 'use cultural and linguistic resources both flexibly and fixedly' (Harissi et al. 2012:540) as they contend with powerful ideologies about gender and sexuality that form part of the broader sociocultural context of interaction. Styling and other strategies are seen to play a key part in a speaker's limited yet real potential to subvert dominant ideologies and 'work free' from social constraints (Coupland 2007:84). Ideologies of gender and sexual identity circulate as discourses in society and can place structural constraints on the resources that are available for gender performances (Cameron 2014). This means they are key to sexual agency (B. King 2014a), for young people must work out how their subjectivities and social identities can become entwined with these constructs as part of performativity.

Performativity is a theory with a 'queer linguistic' legacy and is most commonly associated with the work of Judith Butler (Milani 2018). Performativity as deployed in language research relies on Butler's idea that when we talk, we materialise (evoke) gender ideals by indexing (pointing to) them. Verbal as well as other performances come off as something regardless of intention, mean something, and do their work because they draw on similar performances, reiterating what has worked in the past (Eckert \& McConnell-Ginet 2013). This notion has proved to be indispensable in studies of gender in sociolinguistics, yet Hall (2014) has pointed out that Butler undertheorizes the local. That is, Butler has little to say about the forces that come to bear on these performances and thereby 'tip the scales' between success and failure. To use performativity most productively in ethnographic study one must "localize what constitutes "felicitous" and "infelicitous" performances of gender and sexual identity within the language ideologies circulating in specific communities of practice' (Hall 2014:235). This is the approach taken to performativity in the current study, with such language ideologies and their indexicalities always analysed in relation to field work observations.

\section{Gender and indexicality}

In poststructuralist approaches to gender, an effort is made to steer clear of asking what gender differences are manifest in a given interaction and instead to ask how gender came to make a difference in that interaction (MacKinnon 1987, cited in Cameron 1992). This distinction highlights the need to investigate orientations to NORMS of masculinity and femininity in order to get closer to an understanding of how other social constructions (such as sexual agency) can be in a mutually constitutive relationship with masculinities and femininities (cf Holmes, Marra, \& Lazzaro-Salazar 2017). In terms of norms, Connell (1987; Connell \& Messerschmidt 2005) has theorized that certain norms of masculinity, although they are sociohistorical and subject to change, are hegemonic and so tend to remain ascendant above norms of femininity as well as other norms of masculinity that might 
abound in a given place and time. It is important to keep in mind that hegemonic masculinity is normative but not particularly normal, meaning that no one is likely to fully enact or embody it successfully (Milani 2011). As a theoretical construct, it refers to a normative representation of the most honoured way of being a man (Connell \& Messerschmidt 2005) and is distinguished from other forms of masculinity. This representation is composed of qualities that, defined as 'manly' as part of the hegemonic masculine ideal, create and perpetuate a hierarchical relationship to femininity, ensuring the dominant position of men and the subordination of women (Schippers 2007; Milani 2015). In other words, when indexed (i.e. called forth via language use) these traits are associated with masculinity as positioned hierarchically above femininity. This concept of hegemonic masculinity plays a key role in the analysis.

If one is to fruitfully apply hegemonic masculinity as a theoretical construct during empirical investigation, it becomes necessary to identify its traits within the culture(s) of one's participants. For the purposes of the present study, New Zealand is an industrialised society that has been heavily influenced by Western thought as a legacy of nineteenth-century British imperialism. The participants have all grown up in New Zealand, a colonial context in which regulatory structures of gender and sexuality that are grounded in Oceania sit in tension with British colonial versions (B. King 2017). However, it is the colonial that often holds sway in the institutional setting of schools (B. King 2017). Additionally, as outlined below, Hip Hop culture in New Zealand has been seen to circulate misogynistic tropes and to favour masculinity in its performances (cf. Williams 2017 in South Africa), and this evidence ties HHNL to hegemonic masculinity because of the ideologies sitting behind such positionings.

Furthermore, it is essential to discuss femininity as part of this theoretical framework, for hegemonic femininities also have a powerful influence as discursive ideals that sit behind feminine performances (Charlebois 2010; Schnurr, Zayts, \& Hopkins 2016). As explored above, although feminine abstract ideals in a society can exert a hegemonic form of dominance of their own, masculinity is ascendant in that regard; furthermore, in addition to being merely subordinate, versions of femininity that draw upon traits of hegemonic masculinity are what Schippers (2007:95) terms pariah femininities:

The possession of any one of these characteristics is assumed to contaminate the individual, so by having the one characteristic, an individual becomes a kind of person - a lesbian, a 'slut', a shrew or 'cock-teaser', a bitch.

Thus, displaying a stance of enthusiasm for (hetero)sex, for example, poses a problem for femininity performance by women and girls because it increases the likelihood of being pejoratively labelled a 'slut' or some equivalent, denigrating category, and thus becoming a victim of its stigma (i.e. a sexual pariah). Extensive discourse-analytical studies have borne witness to the magnitude of importance attached by girls in particular to the avoidance of being labelled a slut or any other 
'whore stigma' term (Eckert \& McConnell-Ginet 1995; Sutton 1995; Eckert 2000; Skapoulli 2009; Herring \& Stoerger 2014). In the context of Hip Hop culture, Williams (2017) draws attention to over-sexualization of female participants, and their resistance to being positioned as enthusiastic for sex, demonstrating in his analysis of a Hip Hop dance contest that the women are resistant to being placed in a 'pornified' subject position by a male MC; they are (understandably) reluctant to participate on those terms, and this is consistent with the above mentioned need to manage the slut stigma. This is not to suggest that women completely avoid all association with ways of speaking that, within the immediate context, evoke qualities of hegemonic masculinity, for to do so would be to abandon the use of linguistic resources that have multiple meanings attached to them (Johnson 1997). However, it does mean that accessing them for whatever social purpose might require careful mitigation via the indexing of hegemonically feminine qualities, whether this is done previously, concurrently, or subsequently. During the analysis below it becomes clear that girls who use discursive strategies that performatively draw on hegemonic masculinity via Hip Hop styling and other practices, whether it is done intentionally or not, do need to contend with 'sluttiness' as a 'looming' pariah femininity, and therefore mitigations also indeed become part of the unfolding action.

In summary, to explore the sociolinguistics of Hip Hop styling and sexual agency in a sexuality-education discussion, full attention must be paid to practices that might be indexing certain 'ideals' of gender that hold hegemonic sway over the meanings being created. As Williams $(2015,2017)$ has pointed out, there is also an urgent need to explore these themes in Hip Hop sociolinguistics. The next section outlines the background of Hip Hop globally and locally in order to contextualize the study further.

\section{H I P H OP NATION L A N G U A E}

\section{Connecting to global Hip Hop while 'keeping it real'}

Although Hip Hop had its beginnings in the US, it has extended far beyond its foundational status as an expression of African American culture (Alim, Ibrahim, \& Pennycook 2009; Terkourafi 2010), to become a 'global style community' of the 'Global Hip Hop Nation' (Alim 2009). That is, there is now a worldwide array of local versions of Hip Hop (both in terms of music and everyday talk) that all draw selectively on the ideologies of Hip Hop Culture, thus connecting globally, with each also serving as a localized form of identity expression. Hip Hop Nation Language (HHNL) comprises an array of linguistic features that are borrowed and adapted (Cutler 2015), as well as various Hip Hop cultural concepts (Pichler \& Williams 2016), all of which are used for indexical meaning-making but no longer linked indexically to Black racial identity or African American ethnicity (Cutler 2015). What its deployment more often entails is the 'taking on' of 
stylized personae and speaking through them (Williams 2017), personae that are indirectly indexed by language via certain stances during interaction (Bucholtz 2009). This process of linking stances and personae in interaction is explored in some detail during the analysis.

\section{HIP HOP HEADZ AND HHNL IN NEW ZEALAND}

Pasifika people (a collective term of identification used by people from diverse Pacific island nations) and Māori people (the overarching label with which the indigenous people in New Zealand identify) of the past few generations have grown up with Hip Hop as a form of cultural and personal expression, its presence in New Zealand since the late 1970 s resulting in local interpretations that are consumed alongside other overseas versions. Many Hip Hop 'headz' have drawn on Hip Hop's ideological basis in attempts to 'uplift and educate' Polynesian youth with a local version that speaks to their concerns and biographies (Zemke-White 2001, 2005a; Gibson 2003). This effort by Pasifika performers is a response to a shared feeling of otherness among Pasifika youth ${ }^{1}$ that is echoed among the participants in Hip Hop sociolinguistic studies from around the globe, in places as diverse as Australia (Ross 2018), Brazil (Roth-Gordon 2009; Nascimento 2018), England (Pichler \& Williams 2016), Finland (Westinen 2018), Mongolia (Dovchin 2018), Norway (Cutler \& Røyneland 2015), and South Africa (Williams 2017). The New Zealand based sociological studies cited above have therefore attested to Hip Hop's localization and hint at the existence of what Alim (2009) refers to as 'translocal styling' in communities that bring together the local and the global.

Addressing the question of which aspects of global Hip Hop feature in New Zealand local Pasifika Hip Hop, sociologist Kirsten Zemke-White asserts that what has been maintained is a certain core positivity, but also unfortunately some of the misogyny that 'gangster rap' in particular is famous for (ZemkeWhite 2001). Despite a reported aversion to gangster rap amongst Pasifika Hip Hop performers and a general eschewal of some of its more violent and misogynistic themes (Zemke-White 2005a), there still seems to be some re-inscription of dominant ideas of gender \& sexuality, as has been well documented within nongangster Hip Hop in the US (Alim 2011) and in South Africa (Williams 2015, 2017). Also echoing findings across those locales and many others, Hip Hop cultural concepts in New Zealand tend to favour men's practices (Zemke-White 2005b). Rap battles have not been studied closely in New Zealand, but anecdotes hint that misogyny thrives in that context much more than in rehearsed, recorded performances (Zemke-White 2005a). This observation matches with what Williams has recorded and analyzed in South African rap battles, and he has also observed the ubiquitous performance of braggadocio (bravado) and swagger (coolness) (Williams 2017). Swag is what has elsewhere been described as a type of 'cool marginality' (Cutler \& Røyneland 2015), and it begs for analysis in this study's context as well. However, the particular versions of HHNL used by both 
headz and fans in New Zealand remain underdescribed in the literature, although scholars have attested to the importance of such description. In this way the current study provides an important glimpse into how HHNL is used amongst some Pasifika youth in New Zealand and explores its local social meanings.

\section{CONTEXT OF THIS STUDY}

The original investigation had been conceived as a sociolinguistic case study of sexual agency in a sexuality education classroom. ${ }^{2}$ In order to better understand the macro-level framing of the recorded conversations, and to engage in an appropriate level of transparency, it is essential to first briefly outline my role as a participant researcher in this community of practice. I had been introduced to everyone, staff and students alike, by Mr. Johnson (my patron) and presented as a postgraduate student who was empathetic to their school community. It was on this basis that my participation unfolded. The student participants were all from a Year 12 Health class in New Zealand, placing them at either fifteen or sixteen years of age. In Table 1 below, ${ }^{3}$ the participants are listed under pseudonyms, with their gender and ethnic background indicated. ${ }^{4}$ All of the participants were either born in New Zealand or immigrated as infants. I provide this information mainly as contextual information for the conversational data. The other important participant in these conversations is the teacher, Mr. Johnson, although his words do not appear in this article. He is originally from Australia and had been teaching health/sexuality education in New Zealand for about six years at the time of recording.

Luana features in the current analysis, so it seems appropriate to expend some space introducing her. She enjoyed participating in the school's Pasifika dance club. Her ethnicity was on the class list as Cook Island, but she self-identified as Fijian (born there but emigrated in early childhood). She has dark curly hair and has a solid build and a strong voice. Of all the girls in the class, Luana seemed to least embody hegemonic femininity, and this was a subjectivity she tended to experiment with. During one activity in which groups had to list characteristics of men and women, Luana observed that someone had written 'high voice' on the woman paper. She deepened her voice as much as possible and said, "Whadya mean, high voice!". Then she spoke in a comically squeaky voice, saying, "I have a high voice!". Her group was laughing (Liam and Lito). I found this response interesting because by doing this, Luana used the deeper timbre of her own voice to demonstrate the questionability of that assumption quite effectively. These and other gender nonconforming moments were given emphasis by her tendency to draw on 'Hip Hop swagger' in a similar manner to her male classmate Jay (e.g. high-fiving and using nicknames from male in-groups to address boys). This was marked behaviour for a girl in this community of practice, but Luana consistently performed these personas. 
TABLE 1. Information about the students.

\begin{tabular}{lllll}
\hline \hline & SeX & EтнNicity 1 & EтHNICITY 2 & \multicolumn{1}{c}{ ReLATIONSHIPS } \\
\hline Ben & $\mathrm{M}$ & Niuēan & European & *No close friends in this group \\
Callum & $\mathrm{M}$ & Pākehā & $\mathrm{n} / \mathrm{a}$ & *Friends with Liam (in class) \\
Isaac & $\mathrm{M}$ & Māori & $\mathrm{n} / \mathrm{a}$ & *Friends with Codey and Liam (outside class) \\
& & & & *Friends with Codey and Isaac (outside class) \\
Liam & $\mathrm{M}$ & Pākehā & $\mathrm{n} / \mathrm{a}$ & *Friends with Luana (in class) \\
Luana & $\mathrm{F}$ & Fijian & Cook Island & *Friends with Liam (in class) \\
\hline \hline
\end{tabular}

\section{Sexuality education in New Zealand}

Despite the existence of a robust and advanced curriculum for the subject, the provision (or not) of sexuality education as part of the curriculum at senior level is left to the discretion of schools and is often left out of academic programs (Allen 2005; Jackson \& Weatherall 2010). At the level of junior secondary school, all state schools provide sexuality education in consultation with the local school community, which in most cases ends up comprising a brief unit conducted in third or fourth form, as part of the health curriculum, sometimes by outside providers (e.g. Family Planning New Zealand) and often by the school's teachers. In the present study, the past experiences of class members varied widely in terms of sex education, but ethnographic interviews revealed that all had at least been through the minimal type of program described above. Most described these past experiences as unsatisfying because of the immature behaviour of self and/or peers at the time, and there was a consensus in the class that they wanted to take sex education much more seriously now that they were older. The students in this health class stated clearly that they wanted to be inclusive of all sexual orientations, and were very much against bullying and did not condone it (in line with a school-wide effort), but they acknowledged that they did not enact these inclusive ideals consistently enough. There was also consensus amongst them that the wider school property was not a safe space for gendered or sexual minorities. I myself observed during ethnographic observation that terms like $d y k e$ and lesbo were used as insults by some students in the school grounds. Suffice it to say that a minority sexual subject position would have been a problematic one to fill, even in a relatively inclusive community such as this class. These realities are relevant during the analysis.

With a consensus on the above points established, Mr. J and the students had set out to create a 'safe space' for the discussion of sexuality. During a class meeting in the first weeks of term, a set of guidelines had been collaboratively created, and all had agreed to follow it (e.g. to always listen to others and to be discreet about each other's contributions), and during their ethnographic interviews these guidelines were frequently referred to as a kind of 'touchstone'. But as the sexuality education 
unit approached, a sense emerged (during ethnographic interviews) that this safe space had not been fully achieved, and it was a group of Pasifika girls, including Luana, who had felt somewhat marginalized and were perceived that way by others. After another meeting, the students agreed to cooperate with Mr. J's interventions, and the goal of making everyone feel more comfortable was ultimately achieved. Aside from pointing out some problematic behaviours and imposing a new seating plan, another aspect of Mr. J's classroom management that contributed to the Pasifika students' willingness to participate was the fact that all students were allowed to contribute in ways most comfortable and meaningful for themselves, and this openness included a place for Hip Hop Nation Language.

\section{HHNL IN THIS COMMUNITY OF PRACTICE}

In this community of practice (CofP) sustained Hip Hop swag and braggadocio were done almost exclusively by Māori and Pasifika boys; one Pasifika student, Jay, for example, was fairly typical in that he deployed it consistently in his sense of humour (i.e. as part of language play) and for stance-taking and identity projection when out in the school grounds with his friends. The exception among the girls was Luana, who used Hip Hop styling in a very sustained manner while a few other Pasifika girls used it very rarely, and always in the context of language play. By using it for more than just stance-taking, but rather for a more consistent identity projection, Luana was, like the boys, performatively indexing masculinity locally. It must be acknowledged that there is some circularity to the argument that swag and braggadocio are gendered masculine in this community because boys usually perform them. However, HHNL had been gendered as masculine by habitual use, similar to the use of the term guey among participants in a study by Bucholtz (2009). Braggadocio, as a cultural practice, like use of guey among Bucholtz's participants, is simply not compatible with 'the particular styles of femininity displayed by most girls' in that community (Bucholtz 2009:158).

\section{METHODOLOGY AND ANALYTICAL PROCEDURES}

As revealed in the above sections, when looking at performativity and gendered performances, it is essential to explore what constitutes performances of stance and style. This imperative supports an ethnographic approach, which was taken in this case, with extensive field-note observations serving as a warrant for various analytical interpretations. Analytical procedures here involve identifying linguistic features and cultural practices that relate to Hip Hop Nation Language and their indexical connections (if any) to stances and personae that are involved in the gendering of subjects during the sexuality-education lesson. These features and practices are drawn selectively from broader Hip Hop culture and include 
patterns of intonation, choice of slang terms, cultural references, and more, as is evident in the analysis below.

The activity presented to the students on this day attempts to turn heteronormative thinking on its head (i.e. the entrenched normalization of heterosexuality) by prompting participants to ask and answer questions about heterosexuals or heterosexuality that are stereotypically asked of sexual minorities (Tasker 2000). Whether these pedagogical goals were achieved in the end is not the focus of analysis here. The primary reason that this activity was chosen as a focus for audio recording and analysis was in anticipation of the activity's positioning of students in ways that might prove sexually agentive, or not, or at least stimulate discussions in which sexually agentive subject positions might emerge, prompting the performance of sexual agency and/or the circumvention or recontextualization of such performances.

In a variation of what is often referred to in New Zealand classrooms as the "carousel' discussion method, half of the students remained stationary at desks (and beside an audio recorder-there were eight recorders in the room) while the other half rotated tables after every second question. They went through the questions in sequence and did their best to answer them in interview style. Sections of the recordings were identified in which students were being positioned as sexually agentive, and these were subsequently transcribed and analysed in NVivo. Categories for analysis emerged in a data-driven manner, with agency performance, agency ascription, and responses to these positioning (such as alignments, disavowals, and reworkings) forming categories for analysis. Soon it became clear that meanings were accruing to the various stylized moves and performative indexes identifiable in the data, including those related to Hip Hop styling for the purposes of this article, and these form the basis of the analysis below.

\section{A N A L Y S IS}

Space does not allow for an exploration of responses to all of the questions in the activity; rather, some extracts have been selected for analysis because it has emerged that sexual-agency performances were taking place in these interactions in conjunction with styling, or sexual subject positionings were being actively avoided and/or resignified via styling and other performance strategies.

\section{Following Luana}

As an overview of this section, the analysis follows Luana as she participates in the carousel discussion (see above). In extracts (1)-(3), which occurred about threequarters of the way through the broader activity, Luana had an experience related to sexual agency that she then retold to others as she circulated around the carousel, recontextualizing for each shifting interpersonal framing and, at meso-level, shifting in genres of talk and social roles (e.g. student vs. cousin vs. friend). Her 
negotiations of sexual subject positionings, sexual agency, and social identities were numerous in this section, and they inflected with other interactive work. Most specifically they interacted with norms of masculinity and femininity, norms that she drew upon in an alternating fashion depending on her needs and the context. Styling played an important role as she 'keyed' each stylization (e.g. playful vs. serious), permitting insight into her motivations (Coupland 2007), which ranged from language play, to stance taking, to identity projection depending on the context and her interlocutor. The process of styling served as a discourse strategy that permitted language use to be linked to social identities, and performativity also played an important role as part of inferential meaning making.

In extract (1) below we hear from Liam and Luana. ${ }^{5}$ Over the term together in health class up to this point, the two of them had become friendly. Luana would often 'high-five' Liam as she entered the room and clearly approved of him as a person. In this extract Liam and Luana were temporarily paired together; the final question that they address is number 12: 'Are you offended when a straight person of the opposite sex comes on to you'. As it was her turn to be the asker, Luana put the question to Liam. He answered it and soon turned it back on her, but with a twist that placed the two of them in sexual-agency performance together, creating much laughter. The task of working through a list of preset questions created a meso-level framing by setting a genre in which the institutional role of student was highly relevant and, at least initially, superseded other identities and roles.

(1) Liam and Luana: Would YOU be offended?

1 Luana: are you offended $\uparrow$ when a straight person $\mathcal{\cup}$ of the other sex comes on (.) to you $\Omega$

2 Liam: (4) //not really//

3 Luana: //so if a// GUY came onto YOU liam HOW would you feel

4 Liam: when a straight person of the OTHER (.) sex $\uparrow$ which would be YOU

FEmale $\bigcap$

5 Luana: eh:::*::: $\Omega$

6 Liam: i I wouldn't really be that offended $v$ i wouldn't really mind (.) that much

7 Luana: thank you

8 Liam: (quickly) you're welcome would YOU $\cap$ be offended

(3) if I came onto you right here (.) in this // $\mathrm{xxxx} / /$

9 Luana: ((laughing uproariously))

10 Liam: ((joins in laughing)) that was pretty good there

11 Luana: ((continues laughing uproariously))

12 Liam: ((laughing)) that was funny

13 Luana: ((tears of laughter in voice)) hey YOU'RE another buzz killer brov ((interrupted by teacher for rotation)) 
In turn 1, the question itself, by suggesting that one could take offence in this situation (or fail to), ascribed agency to the sexual subject of the imagined situation. Additionally, the simple present construction and its assumption of a wealth of experience with 'being come on to' and responding actively to it, placed the respondent in the position of an on-going sexual agent who was anything but passive. In this indirect manner, the question therefore recognised the respondent's agency. The classroom activity thus served as a meso-level frame and positioned Luana, in her student role, as sexually agentive, making her own sexuality highly relevant to the task at hand. This meso-level framing began to interact with the macro-level framing of gender and society at the sociocultural level and with the micro-level framing of her personal relationship with Liam (and later others). Thus it instigated a rather complicated process in which Luana had to 'juggle' various identity performances simultaneously in relation to sexuality. One of the ways that she achieved this was by drawing upon features of HHNL, a process that becomes evident below.

In turn 3, Luana misunderstood the question, thinking that Liam was being asked to respond to an advance from another man. Liam corrected her, and in so doing ascribed sexual agency to her, and he did so in direct relation to himself. In turn 4 he said:

when a straight person of the OTHER (.) sexU

which would be YOU $\cap$

FEmale $\bigcap$

To change the focus of the question in this way was an interesting choice on Liam's part, for Luana was then positioned as having asked Liam 'Would you be offended if I came on to you?' and this was not the original 'force' of the question at all. This shift in interpersonal framing positioned the two speakers differently in relation to one another and recontextualized the interaction quite suddenly. Luana did not actively resist this positioning, and so Liam continued, saying quite plainly that he would not really mind. Luana responded by saying "thank you" and Liam said "you're welcome" and the two of them aligned to sexually agentive subject positions, and this in relation to one another. It is also important to observe that there had been a complication of role and spoken genre in this interaction, with the mesolevel framing of 'class activity' and its concomitant student roles receding. There is a shift in genre emerging, moving more towards intimate conversation as certain 'boundaries' were crossed in terms of mutual positioning. This framing began to have recontextualizing effects on the interaction.

In turn 8, Liam then turned the question around, saying "would you be offended if I came on to you right here" and the rest of what he said was eclipsed by Luana's explosive laughter, which continued for some time. In the absence of post-recording member checking (unfortunately not consented to by the participants due to their busy lives), it is difficult to be certain about Liam's intention in this exchange (i.e. verbal play vs. sincerity), but it is clear that he had altered the key of the 
interaction. Regardless of his intention, Luana applied her own keying via her laughter, and Liam aligned to her treatment of it as a humorous incident. Liam's use of the term "right here" had 'changed the game', recontextualizing and intensifying their mutual sexual agency from a hypothetical 'would' into the 'here and now' (or there and then, if you prefer). It was a sexual agency performance on his part. For Luana's part, by laughing loudly (and quite authentically, with tears in her voice by the end) she responded to the sexual subject position that had been ascribed her, one that she had aligned to a moment before when it had still been hypothetical and framed less ambiguously as on-task classroom discourse in line with their role as students. By keying Liam's question as a very funny joke (and calling him a "buzz killer", someone who ruins your good time or good mood), Luana called an end to the game and performatively resignified their 'sexual agent' identity projections as play rather than overt sexuality. Finally in turn 13 we see the first instance of Hip Hop styling by Luana, which can be defined as vowel lengthening, syllable expansion and contraction, and stress and rhythm that approximates African American Vernacular English (AAVE) (Cutler 1999). Her switch to this type of styling was brief here but evidenced by her use of the HHNL inspired slang term 'buzz killer' and emphatic stress pattern. It is the first hint we get of a stance that Luana took, one that pointed to a persona of the swag Hip Hop head who is in control (Williams 2017). It is also the first hint of an oppositional stance indicating that she did not enjoy being positioned that way by Liam.

It is important to note that the power dynamics in this exchange shift considerably depending on whether it was a man or a woman placed in the position of being the 'hypothetical' recipient of sexual attention. Liam responded quite frankly (i.e. keyed in a sincere tone), saying that he would not be offended by an advance from Luana, but when Luana was asked to assess her own response to Liam's 'hypothetical' advances, she avoided giving an answer. Granted, as observed above, Luana was responding after Liam had intensified the situation by shifting their interpersonal framing; however, it might be that she 'dodged' the question because the answer would constitute a different social-identity performance for a young woman. Luana had to navigate the attendant slut stigma, and perhaps the 'right here, right now' framing of Liam's question was too much of a social risk for her to take. Luana soon moved on in the rotation to work with other groups, who had been unable to help overhearing her raucous laughter, and she readily related the incident. These reports evolved into a narrative, and the telling led to further recontextualizations and performances in relation to sexuality, sexual agency, and Hip Hop styling.

The first person to hear about it was Callum, someone who knew Liam fairly well in the context of this CofP. They were friends in health class, but they did not 'hang out' together otherwise, according to their ethnographic interviews. As she did with Liam, Luana saw Callum, as well as Ben and Isaac (who feature as listeners in extract (4)), as her classroom friends, and seemed to like them and feel comfortable with them. In extract (2) Callum inquired about her conversation with Liam, and she then related the incident, adjusting for their interpersonal 
framing by drawing on Hip Hop styling as part of stance-taking and thus social identity negotiation.

(2) Callum and Luana, part 1: He killed my buzz

1 Luana: ((crossing from previous table, where Liam remains)) MY god that's just SO bad (.) ((short loud laugh))

2 Callum: what'd liam SAY to you

3 Luana: aw ((almost laughs again))

cause we were on number:::

twelve $\uparrow$ ((short laugh))

aw::: ((starts laughing again))

(.) and I ASKED him the question he was like

no i wouldn't be offended

would YOU be offended if i came on to you (.) RIGHT now $\uparrow$

i was like WHAT the F::.:.::

((high pitch)) he KILLEd my BUZZ $\curvearrowleft$

4 Callum: ((laughing))

5 Luana: i mean I $\uparrow$ just can’t acCEPT $\uparrow$ that shit callum $\uparrow$

6 Callum: ((laughs a bit))

7 Luana: that's just unacCEPT $\uparrow$ able $\downarrow$

i mean it's not in my DICtionary $\uparrow$

it's not in my BOOKS $\uparrow$

(1) ((more evenly)) HE'S in my buzz killer book

8 Callum: when did you=

9 Luana: $=$ HIT me with (.) number $13 \curvearrowleft$

SAY it out loud $\bigcap$

In the retelling, Luana related being placed in a sexually agentive subject position by Liam and actively resisted this positioning, rekeying the telling of the incident with less humour and less benignly than in extract (1) while adjusting for a different interpersonal framing (i.e. reporting what happened to another boy who was Liam's friend). Her intonation throughout most of the extract was widely varying and therefore came across as emphatic. It is at this point that Luana began a sustained use of Hip Hop styling. As a discourse strategy it permitted her to imply a number of meanings, which then had to be managed in turn.

Callum was of course unaware of the precise way in which the original incident had unfolded, but late in turn 3 Luana reported the words that had shifted the framing of her discussion with Liam and thus their interactional context. She reported that Liam had said "would YOU be offended if i came on to you (.) RIGHT nowu", and this was a fair representation of what he had said (except that Liam said "right here" instead of "right now"). She then immediately quoted her thoughts at the time, saying "i was like WHAT the F:::::" thereby beginning a series of statements in which she recontextualized the events for Callum as something that she could barely even comprehend 
(see extract (2), lines 6 and 7). She began to repair her social identity as a young woman in the class and work through the implications for her own subjectivity, 'trying out identity meanings' in the process (Harissi et al. 2012). In telling Callum what had happened, she essentially had to reveal that Liam had projected sexual agency onto her in a very direct and immediate sense. The subsequent turns constituted a stance of resistance to that positioning in which Luana resignified sexual agency into a form that was more socially useful to her, drawing on Hip Hop styling in the process.

To begin with, Luana said in turn 7 "that's just unacCEPT $\uparrow a b l e \downarrow$ ", and this is where the resignification began as she managed her interpersonal framing with Callum and her other classmates. She then said (again in turn 7), "it's not in my DICtionary $\uparrow "$, which could be interpreted as a way of saying that she had found herself illequipped for the situation she and Liam ended up in. By expressing her incredulity, however, she separated herself from the socially problematic sexual agency that Liam had evoked, asserting her own innocence. In this way she made it clear that she was a reluctant participant, and the slut stigma was held at bay. However, her deployment of Hip Hop styling in turns 7-9 carried certain implications of masculinity via braggadocio. Therefore this aspect of inferential meaning bolstered her act of resistance by performatively indexing dominance and swag control, yet it also called forth other social-identity positionings that then had to be managed in turn.

The following dialogue in extract (3) constitutes a continuation of the previous extract. There is no time gap between the two; rather, after explaining to Callum what had happened with Liam, they started to address question 13 (turns 1 and 2 are a repeat of the final turns in extract (2)).

(3) Callum and Luana, part 2: i LOVE boys

\begin{tabular}{|c|c|c|}
\hline 1 & Callum: & when did you= \\
\hline 2 & Luana: & $=$ HIT me with (.) number $13 \Omega$ \\
\hline & & SAY it out loud $\bigcap$ \\
\hline 3 & Callum: & when did you choose your sexual orientation \\
\hline 4 & Luana: & i do NOT know what that means \\
\hline 5 & Callum: & $\begin{array}{l}\text { like when did you } \\
\text { when did you choose what sex you LIKE }\end{array}$ \\
\hline 6 & Luana: & $\begin{array}{l}\text { (2) at a very young age } \uparrow \\
\text { at about ten } \uparrow \text { i guess::: } \\
\text { (booming voice) i LOVE boys:: }\end{array}$ \\
\hline 7 & Callum: & (laughing a bit) ((rare for Callum)) \\
\hline 8 & Luana: & $\begin{array}{l}\text { i love them } \mathrm{S}:: \mathrm{O} \text { much } \bigcap \\
\text { (1) oh they are just SUCH good workers:: } \\
\text { (2) in BED }\end{array}$ \\
\hline 9 & Callum: & (laughing a bit) \\
\hline 10 & Luana: & yeah \\
\hline
\end{tabular}

(1) thank you

(1) YOUR turn 
In turn 1, Callum began to ask question 13, and Luana oriented to his efforts to return the framing to one of on-task discussion and student roles, saying in turn 2 , "HIT me with (.) number $13 \curvearrowleft$ SAY it out loud $\Omega$ ". This way of talking marked a return to Hip Hop styling evidenced by vowel lengthening, syllable expansion and contraction, and stress and rhythm. In voicing her contribution in this way, Luana commanded the listener and indexed a swag, tough, street-wise 'readiness for anything', and so it is a solid example of braggadocio (Williams 2015, 2017), and the indirect indexing of a persona that is masculine gendered in the circuits of Hip Hop globally (Alim 2011; Williams 2017) and locally in New Zealand (Zemke-White 2005b). As outlined earlier in this article, my ethnographic fieldnotes indicate that Luana commonly deployed this style in the context of this CofP, and in this way she stood out from all the other girls in the class, including the other Pasifika girls because they rarely deployed this style, and if they did it was a less sustained performance. Throughout this extract, Luana maintained this Hip Hop styling, and it had specific effects that were useful to her.

Confronted with the term sexual orientation, Luana was unable to understand it and admitted so freely in turn 4. Callum rephrased it in a way that she understood, saying "when did you choose what sex you LIKE". Luana replied that she "chose" at a very young age (citing age ten) and then went on to engage in a vociferous performance of sexual desire for boys. In turn 6, Luana said " $\mathrm{i}$ LOVE boys::" in a voice that certainly reached well beyond the ears of her discussion partner Callum. There was a din of voices in the room, with seven other similar conversations taking place, however her assertion of attraction to boys seems to have been intended for a broader audience. Perhaps this audience also includes myself as the researcher via the recording device. As pointed out in the previous section, Luana had managed to keep the slut stigma at bay, but at this point when asked about sexual orientation, she took a stance, emphasising that she was indeed sexually attracted to boys, and in fact very much cool and in control, sexually speaking. She 'loved boys', and in fact performed sexual agency by suggesting that she had firsthand experience with the 'work' that boys do 'in bed'. And so, braggadocio is once again called forth.

Subsequent to her earlier assertions to Callum that she had been a reluctant recipient of Liam's sexual attention, this performance of sexual agency could be read as a follow-up repair to her performance of sexual identity/orientation. Perhaps the 'spectre of homosexuality' (Cameron 1997:61) was making its presence felt as a result of common associations between masculinity and lesbian identity in the preunderstood social ecology (McElhinney 1995; Morrish \& Sauntson 2007; Jones 2012, 2015). Therefore, it could be argued that Luana felt motivated to distance herself from a lesbian 'butch' identity, which had been observed to be problematic in this school and peer group context (see CONTEXT OF THIS STUDY). As the next extract demonstrates, Luana began to baldly assert a straight identity to the next group while she continued working to come to terms with her conversation with Liam. 
It could also be argued that Luana's sustained Hip Hop styling added to the need for her to go bald on record about her attraction to men. As observed earlier, Hip Hop braggadocio is masculine-gendered both because of its positioning in New Zealand (and global) Hip Hop culture but also because of habitual practices locally in which it was done almost exclusively by boys. The Hip Hop styling observed in this CofP bears some of the hallmarks of hegemonic masculinity outlined earlier in this article (i.e. hierarchy, dominance, and overt heterosexuality). It is interesting that Luana's stylized expression of sexual agency in "I LOVE boys, they're such good workers in bed" could be read as a display of 'heterosexual' attraction and dominance, two elements in this list. Ethnographic observations revealed that at other times Luana drew upon tough threats of confrontation (e.g. 'Let's take it over there') and continual swag references to hierarchy in that whichever classroom group she might find herself in was always framed as 'the best'. This sustained use of HHNL features and practices and their indexed stance could, on her part, be argued to be a projection of a masculine gender identity via the enactment of a gendered persona. However, aligning to a cultural discourse of dominance does not always entail a 'desire for masculinity' (Kiesling 2011), or a desire to be taken as masculine. Rather, it could be more directly related to a desire to 'reject overtly feminine styles' (Jones 2014:183) and thus rework the category of 'woman' or 'girl'. As the carousel activity turned one more rotation, and Luana once again adjusted the interpersonal framing to accommodate new interlocutors (i.e. boys once again), it began to emerge that she did remain committed to being 'taken as a girl' on the heterosexual market. And styling once again allowed her to convey meanings for her audience.

(4) Luana, Ben, and Isaac: WHAT the FUCK!

1 Isaac: ((reading aloud)) what have been your reactions to answering these //questions//

2 Ben: //oh uhhh// to the questions we've answered $v$

3 Luana: I found it SO well until it came to number twelve that LIam was just being a little SHIT $\cup$

4 Ben: ((pointing at recorder and laughing))

5 Isaac: ((laughing))

6 Luana: ((whispering into mic)) i take that back

7 Ben: why::

8 Luana: well:::: $\uparrow$

(1) I asked him if he was ofFENDed $\uparrow$ when a straight PERson $\uparrow$ M::::E::৩ STRAIGHT $\checkmark$

((high pitch and squeaky)) i AM straight $\bigcap$ $\uparrow$

(1) of the other sex comes on (.) to you $\uparrow$ and he goes

(1) no $\bigcap$ (.) i don’t feel $\bigcap$ (.) offended $\bigcap$ (.) by (.) a (.) girl $\bigcap$ (.) that comes on to me $\cap$ 


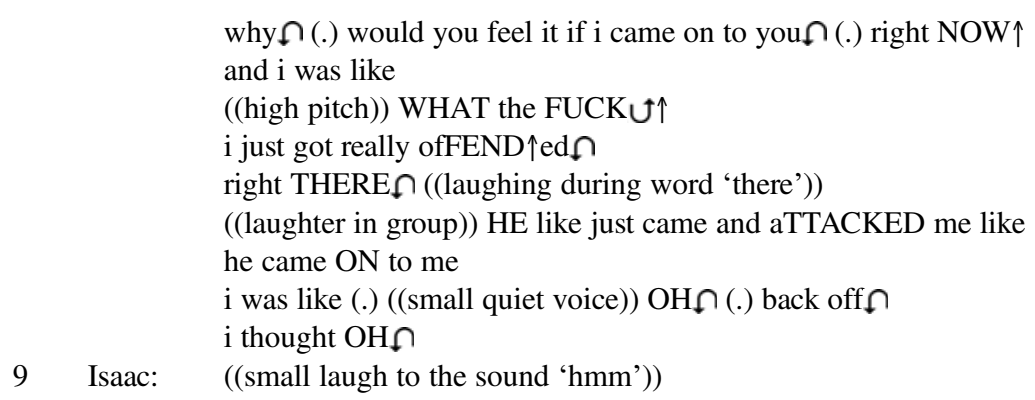

Speaking to Ben and Isaac, Luana related her evolving story about the incident with Liam. She continued to use Hip Hop styling in turns 3-8. At the beginning of turn 8 Luana raised pitch and said pointedly "M::::E:: $\cup$ STRAIGHT $\cup$ " and deployed a scooping intonation, one that indexed a stance saying that Ben and Isaac might require some convincing as to her 'straightness'. She then escalated the emphasis even further, saying in a high, squeaky voice with a high rising and then low scooping intonation on the word 'straight', "i AM strai $\uparrow$ ghtu". Ben and Isaac had said nothing to indicate any doubt about this stance, yet she repeatedly indexed it in a tone that suggested they required convincing. This is perhaps because she was preparing to tell them about her rejection of Liam's come on. She quoted her thoughts once again (as with Callum before) saying "i was like

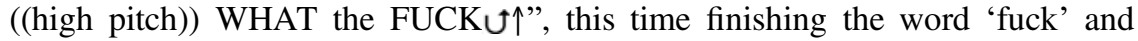
using a deeply scooped and then high rising ending, the effect of which was again to communicate incredulity. She then asserted for the first time that she had indeed been offended, which is of course what Liam's question had been (i.e. Would you be offended if I came on to you right here...). It seems that Luana had finally made sense of her own reaction. As before, this stance of reluctant participation and offence permitted her to avoid the slut stigma. Her prior emphatic insistence that she was straight balanced this achievement with the need to come across as being attracted to boys in spite of that reluctance and in spite of her projections of a masculine identity (either intentionally or otherwise) via Hip Hop styling and its citations of hegemonic masculinity (i.e. a pariah femininity) in the enactment of masculinized braggadocio and swag.

Finally it was through femininity performance, rather than bald-on-record assertions, that Luana rounded off her navigation of sexual agency. She finished her story with further quotation of her thoughts at the moment Liam 'came on' to her, but her styling changed considerably. Using a very different approach, stripped of the swagger and braggadocio of her earlier Hip Hop styling, she summed up her internal reaction as " $\mathrm{OH} \cap$ (.) back off $\curvearrowleft \mathrm{OH} \curvearrowleft$ ". Each phrase was high pitch and breathy, with low rising then falling tone, which could be described as 'lilting'. In Hall's now-classic telephone sex-worker study (1995:200), the workers drew on a similar breathy, lilting style to sound more stereotypically 
feminine to their clients, and so it is plausible to suggest that Luana was indexing similar feminine stereotypes (and perhaps 'emphasised femininity' - Connell 1987) via this persona. Sitting in contrast with the previous performances, an effect of this shift in style was a femininity performance drawing not on hegemonic masculinity but instead hegemonic femininity. By the end of the story, Luana thus reconciled straight identity projection with her rejection of a sexually agentive subject position by associating that rejection with femininity. As Kulick (2003) has argued, to say no to a sexual advance is to (heteronormatively) call forth the sexual subject position 'woman'. It is therefore interesting that femininity performance is where Luana's navigation took her.

\section{ISCUSSION A N C O N C L USION}

By claiming to love boys in bed, Luana repaired the damage done to her 'straight' identity that had resulted from her use of Hip Hop styling and rejection of Liam's 'advance'. As a consequence of drawing on hegemonic masculinity, however, she was then propelled into further repair, this time of her femininity. She found herself placed in a very 'real' (i.e. nonhypothetical) position of sexual agency in relation to Liam, and this led her to rekey sexual agency as a joke. In retelling her experience to others, she performed disavowals of sexual agency in order to distance herself from the slut stigma, but these disavowals reveal that she was in a double bind. By rejecting the idea of sexual agency in relation to Liam, she was compelled to acclaim different-sex attraction. By doing so in the Hip Hop swag persona that she adopted (i.e. with a stance of dominance in this CofP), she indirectly indexed hegemonic masculinity regardless of what her intention might have been, thus raising the spectre of lesbian identity, a 'pariah' femininity in the heterosexual market of this secondary school, which has to be banished through bald-on-record claims of straight identity and a performance of emphasised femininity.

Luana used a cluster of semiotic resources to create Hip Hop styling while taking a number of stances related to the course material and Liam's positioning of her. She selected particular features to perform braggadocio, which imposed an indirect indexical link to masculinity as a result of its habitual use patterns in this community and Hip Hop culture more broadly. School and gender norms both imposed regulatory frameworks that these performances were interpreted against. Her stances were seen to have interpersonal consequences that had to be managed in turn, and these interpersonal effects cannot be separated from gender. Lack of research prevents knowledge of how braggadocio functions in practice in the rest of New Zealand, but as a circulating resource it seems to have developed this masculine indexicality via local acts of stance-taking as outlined in the ethnographic notes (i.e. during moments of aggressive and/or competitive talk).

The data analysed in this article support the notion that gender, sexual identity, and agency are interconnected, but not in a way that supports a normative conception of how sex, gender, and sexuality 'should' be aligned (i.e. in which masculine 
gender is 'built' on male bodies and feminine gender on female ones). This is because it is not maleness and femaleness but masculinities and femininities (and their close associations with sexual identities such as 'lesbian' or 'straight') that must be negotiated if one is to align to a sexually agentive subject position.

From the point of view of sexuality education, it seems that providing students with a learning community in which they can 'safely' experiment with sexually agentive subject positions in conversation is beneficial in that it allows them some space to negotiate how sexual agency might fit with their other identifications and social identities. This approach to sexuality education of course requires careful management and some training, with which the teacher of this class was well equipped, and he was watchful and diligent in providing follow-up care and guidance. Relinquishing a didactic approach to sexuality education and embracing a community-based, discussion-oriented paradigm can result in reconciliation between sexual agency and the circulating discourses that complicate its realisation. Thus Luana's experimentation with identity meanings as she moves around the 'carousel' represents a valuable learning experience for her, preparing her for future experiences of being placed in sexually agentive subject positions. The transformative potential of performativity can be accessed.

By examining how Hip Hop styling was used in Luana's negotiations of identities and stances, it is possible to begin an exploration of how engagement with Hip Hop cultural practices might mediate educational processes in diverse subjects and locations. The study was not at first conceived with this insight in mind; rather, the emergence of Hip Hop styling was unexpected yet highly relevant. As a bit of happenstance, the interaction analysed here has provided a view of the type of consciousness raising that can take place when students are encouraged to express themselves in ways relevant to their own lives (e.g. via HHNL, etc.), as was the case in Mr. J's class. As an ethnographic participant observer, I maintain that the freedom to use Hip Hop styling evoked a 'safe space' (Alim 2011) for Pasifika students in the class who had previously felt rather marginalized. This is not to imply that what unfolded in Luana's case is an example of best practice; rather the point is that these insights open up vistas for extensive further research into how the use of diverse linguistic resources in sexuality-education discussions mediates those experiences. Further studies are certainly needed, particularly ones that explore these discursive processes from an 'intersectional' point of view in which other aspects of selfhood such as class, ethnicity, or religious belief are seen to interact with gender and sexuality in dynamic ways (Levon 2015). Nevertheless the findings here have demonstrated that it is often through stylistic acts that young people might become the assured sexual selves they need to be in order to navigate the risks involved with sexual activity (for these are real), but also to access the pleasures of sexuality as part of a healthy life. Thus we see that styling (Hip Hop or otherwise) still stands to contribute a great deal more to our understanding of gender and language, but also of sociolinguistics more generally. 


\section{A P P E N D IX: TR A N S C R IP TION C ONVENTIONS}

// overlapping speech

$=\quad$ latching, or no perceptible space between utterances

(1) elapsed time of silence in seconds

(.) a tiny gap, less than one second

$:$ prolongation of the immediately prior sound

CAP especially emphasized sounds compared to surrounding talk (including 'I')

() prosodic contributions, e.g. (laughter).

(()) author's descriptions rather than transcriptions

$\uparrow \quad$ rising intonation in the preceding syllable

$\downarrow \quad$ falling intonation in the preceding syllable

$\checkmark \quad$ falling and then rising intonation in the preceding syllable

$\curvearrowleft \quad$ rising and then falling intonation in the preceding syllable

\section{N O T E S}

*I would like to thank Janet Holmes for her support and supervision during this research project as well as Meredith Marra for mentorship and advice. In addition, I want to thank Louisa Allen, Paul Baker, and Martha Pennington for valuable comments on the original version of the analysis. Finally, I extend my heartfelt thanks to the students and teacher who participated in this study, and to Jenny Cheshire and the reviewers.

${ }^{1}$ Although facing their own postcolonial struggles, the Māori have been at least symbolically included in New Zealand from its beginnings, the Treaty of Waitangi between Māori and the Crown in 1840 promising them status as British subjects (Orange 2013) and as 'two peoples in one country' with the British settlers (Hill 2010:294). Transnational Pasifika peoples in New Zealand have thus had to assert a place of social inclusion in the resultant 'bicultural' model that accompanied the modern reincarnation of the Treaty of Waitangi.

${ }^{2}$ Ethics approval for this research was granted by the Human Ethics Committee of Victoria University of Wellington, New Zealand.

${ }^{3}$ All names used are pseudonyms, and human ethics approval for this research was granted by the Human Ethics Committee, Victoria University of Wellington, New Zealand.

${ }^{4}$ Pākehā is a term of disputed etymology that has come to mean white, native born New Zealanders in some formulations (e.g. M. King 1999), and in others refers to the descendants of white settler colonists of any origin.

${ }^{5}$ Transcription conventions are given in the appendix.

\section{R E F E R E N C E S}

Ahearn, Laura M. (2010). Agency and language. In Jürgen Jaspers, Jan-Ola Östman, \& Jef Verschueren (eds.), Society and language use, 28-48. Amsterdam: John Benjamins.

Alim, H. Samy (2009). Translocal style communities: Hip Hop youth as cultural theorists of style, language, and globalization. Pragmatics 19(1):103-27.

- (2011). Gobal ill-literacies: Hip Hop cultures, youth identities, and the politics of literacy. Review of Research in Education 35(1):120-46.

—_ Awad Ibrahim; \& Alastair Pennycook (eds.) (2009). Global linguistic flows: Hip Hop cultures, youth identities, and the politics of language. London: Routledge.

Allen, Louisa (2005). Sexual subjects: Young people, sexuality and education. London: Palgrave. 


\section{HIP HOP HEADZ IN SEX ED}

Androutsopoulos, Jannis (2009). Language and the three spheres of hip hop. In Samy H. Alim, Awad Ibrahim, \& Alastair Pennycook (eds.), Global linguistic flows: Hip Hop cultures, youth identities, and the politics of language, 43-62. London: Routledge.

Bell, Allan (2016). Succeeding waves: Seeking sociolinguistic theory for the twenty-first century. In Nikolas Coupland (ed.), Sociolinguistics: Theoretical debates, 391-414. Cambridge: Cambridge University Press.

Bucholtz, Mary (2001). The whiteness of nerds: Superstandard English and racial markedness. Journal of Linguistic Anthropology 11(1):84-100.

- (2009). From stance to style: Gender, interaction, and indexicality in Mexican immigrant youth slang. In Alexandra Jaffe (ed.), Stance: Sociolinguistic perspectives, 146-70. New York: Oxford University Press.

Cameron, Deborah (1992). 'Not gender difference but the difference gender makes'-Explanation in research on sex and language. International Journal of the Sociology of Language 94(1):13-26.

Cameron, Deborah (1997). Performing gender identity: Young men's talk and the construction of heterosexual masculinity. In Sally Johnson \& Ulrika Meinhoff (eds.), Language and masculinity, 47-64. Malden, MA: Blackwell.

(2005). Language, gender and sexuality: Current issues and new directions. Applied Linguistics 26(4):482-502.

- (2014). Gender and language ideologies. In Susan Ehrlich, Miriam Meyerhoff, \& Janet Holmes (eds.), The handbook of language, gender and sexuality, 282-96. Malden, MA: Wiley.

Campbell-Kibler, Kathryn (2008). I'll be the judge of that: Diversity in social perceptions of (ING). Language in Society 37(5):637-59.

Charlebois, Justin (2010). Discursive construction of hegemonic femininity. In Janet Holmes \& Meredith Marra (eds.), Femininity, feminism and gendered discourse, 41-58. Newcastle upon Tyne: Cambridge Scholars.

Connell, Raewyn W. (1987). Gender and power. Cambridge: Polity Press.

— \& James W. Messerschmidt (2005). Hegemonic masculinity: Rethinking the concept. Gender and Society 19(6):829-59.

Coupland, Nikolas (2007). Style: Language variation and identity. Cambridge: Cambridge University Press.

Cutler, Cecilia A. (1999). Yorkville crossing: White teens, Hip Hop and African American English. Journal of Sociolinguistics 3(4):428-42.

(2015). White hip-hoppers. Language and Linguistics Compass 9(6):229-42.

, \& Unn Røyneland (2015). Where the fuck am I from? Hip-Hop youth and the (re)negotiation of language and identity in Norway and the US. In Jacomine Nortier \& Bente A. Svendsen (eds.), Language, youth and identity in the 21st century, 139-64. Cambridge: Cambridge University Press

Dovchin, Sender (2018). Dissatisfaction and dissent in the transmodal performances of hip-hop artists in Mongolia. In Andrew S. Ross \& Damian J. Rivers (eds.), The sociolinguistics of hip-hop as critical conscience: Dissatisfaction and dissent, 191-211. Basingstoke: Palgrave Macmillan.

Eckert, Penelope (2000). Linguistic variation as social practice: The linguistic construction of identity in Belten High. London: Blackwell.

(2012). Three waves of variation study: The emergence of meaning in the study of sociolinguistic variation. Annual Review of Anthropology 41(1):87-100.

- \& Sally McConnell-Ginet (1995). Constructing meaning, constructing selves: Snapshots of language, gender, and class from Belten High. In Kira Hall \& Mary Bucholtz (eds.), Gender articulated: Language and the socially constructed self, 469-507. London: Routledge.

- \& — (2013). Language and gender. 2nd edn. Cambridge: Cambridge University Press.

Gibson, Lorena (2003). Versioning for the love of it: Hip-Hop culture in Aotearoa. Palmerston North: Massey University MA thesis. 


\section{B RIAN W. KING}

Hall, Kira (1995). Lip service on the fantasy lines. In Kira Hall \& Mary Bucholtz (eds.), Gender articulated: Language and the socially constructed self, 183-216. London: Routledge.

(2014). Exceptional speakers: Contested and problematized gender identities. In Susan Ehrlich, Miriam Meyerhoff, \& Janet Holmes (eds.), The handbook of language, gender and sexuality, 220-39. Malden, MA: Wiley.

Harissi, Maria; Emi Otsuji; \& Alastair Pennycook (2012). The performative fixing and unfixing of subjectivities. Applied Linguistics 33(5):524-43.

Herring, Susan C., \& Sharon Stoerger (2014). Gender and (a)nonymity in computer-mediated communication. In Susan Ehrlich, Miriam Meyerhoff \& Janet Holmes (eds.), The handbook of language, gender and sexuality, 567-86. Malden, MA: Wiley.

Hill, Richard S. (2010). Fitting multiculturalism into biculturalism: Māori-Pasifika relations in New Zealand from the 1960s. Ethnohistory 57(2):291-319.

Holmes, Janet; Meredith Marra; \& Mariana Lazzaro-Salazar (2017). Negotiating the tall poppy syndrome in New Zealand workplaces: Women leaders managing the challenge. Gender and Language 11(1):1-29.

Jackson, Sue, \& Ann Weatherall (2010). The (im)possibilities of feminist school based sexuality education. Feminism \& Psychology 20(2):166-85.

Jaffe, Alexandra (2009). Introduction: The sociolinguistics of stance. In Alexandra Jaffe (ed.), Stance: Sociolinguistic perspectives, 3-28. Oxford: Oxford University Press.

Johnson, Sally (1997). Theorising language and masculinity: A feminist perspective. In Sally Johnson \& Ulrike H. Meinhof (eds.), Language and masculinity, 8-26. Oxford: Blackwell.

Jones, Lucy (2012). Dyke/girl: Language and identities in a lesbian group. Basingstoke: Palgrave Macmillan.

(2014). 'Dolls or teddies?': Constructing lesbian identity through community-specific practice. Journal of Language and Sexuality 3(2):161-90.

- (2015). Masculinity in lesbian discourse: The case of butch and femme. In Tommaso M. Milani (ed.), Language and masculinities: Performances, intersections, dislocations, 174-96. London: Routledge.

Kiesling, Scott F. (2011). The interactional construction of desire as gender. Gender and Language $5(2): 213-39$.

King, Brian W. (2014a). Inverting virginity, abstinence, and conquest: Sexual agency and subjectivity in classroom conversation. Sexualities 17(3):310-28.

- (2014b). Tracing the emergence of a community of practice: Beyond presupposition in sociolinguistic research. Language in Society 43(1):61-81.

(2017). Querying heteronormativity among transnational Pasifika teenagers in New Zealand: An Oceanic approach to language and masculinity. Journal of Sociolinguistics 21(3):442-64.

King, Michael (1999). Being Pākehā now: Reflections and recollections of a white native. Auckland: Penguin.

Kramsch, Claire (2012). Imposture: A late modern notion in poststructuralist SLA research. Applied Linguistics 33(5):483-502.

Kulick, Don (2003). No. Language and Communication 23(2):139-51.

Levon, Erez (2015). Integrating intersectionality in language, gender, and sexuality research. Language and Linguistics Compass 9(7):295-308.

MacKinnon, Catharine A. (1987). Feminism unmodified: Discourses on life and law. Cambridge, MA: Harvard University Press.

McElhinney, Bonnie (1995). Challenging hegemonic masculinities: Female and male police officers handling domestic violence. In Kira Hall \& Mary Bucholtz (eds.), Gender articulated: Language and the socially constructed self, 217-44. London: Routledge.

Milani, Tommaso M. (2011). Introduction: Re-casting language and masculinities. Gender and Language 5(2): 175-86. 


\section{HIP HOP HEADZ IN SEX ED}

(2015). Theorizing language and masculinities. In Tommaso M. Milani (ed.), Language and masculinities: Performances, intersections, dislocations, 8-33. London: Routledge.

(2018). Queer performativity. In Rusty Barrett \& Kira Hall (eds.), The Oxford handbook of language and sexuality. Oxford: Oxford University Press, to appear.

Moore, Emma, \& Robert J. Podesva (2009). Style, indexicality, and the social meaning of tag questions. Language in Society 38(4):447-85.

Morrish, Liz \& Helen Sauntson (2007). New perspectives on language and sexual identity. London: Palgrave Macmillan.

Nascimento, André Marques do (2018). Counter-hegemonic linguistic ideologies and practices in Brazilian indigenous rap. In Andrew S. Ross \& Damian J. Rivers (eds.), The sociolinguistics of hip-hop as critical conscience: Dissatisfaction and dissent, 213-35. Basingstoke: Palgrave Macmillan.

Ochs, Elinor (1992). Indexing gender. In Alessandro Duranti \& Charles Goodwin (eds.), Rethinking context: Language as an interactive phenomenon, 335-38. Cambridge: Cambridge University Press.

Orange, Claudia (2013). The Treaty of Waitangi. Wellington: Bridget Williams Books.

Pichler, Pia, \& Nathaniel Williams (2016). Hipsters in the hood: Authenticating indexicalities in young men's Hip-Hop talk. Language in Society 45(4):557-81.

Ross, Andrew S. (2018). '77\% of Aussies are racist': Intersections of politics and hip-hop in Australia. In Andrew S. Ross \& Damian J. Rivers (eds.), The sociolinguistics of hip-hop as critical conscience: Dissatisfaction and dissent, 69-99. Basingstoke: Palgrave Macmillan.

Roth-Gordon, Jennifer (2009). Conversational sampling, race trafficking, and invoking the gueto in Brazilian Hip-Hop. In Samy H. Alim, Awad Ibrahim, \& Alastair Pennycook (eds.), Global linguistic flows: Hip Hop cultures, youth identities, and the politics of language, 63-78. London: Routledge.

Schippers, Mimi (2007). Recovering the feminine other: Masculinity, femininity, and gender hegemony. Theory and Society 36(1):85-102.

Schnurr, Stephanie; Olga Zayts; \& Catherine Hopkins (2016). Challenging hegemonic femininities? The discourse of trailing spouses in Hong Kong. Language in Society 45(4):533-55.

Silverstein, Michael (2003). Indexical order and the dialectics of sociolinguistic life. Language \& Communication 23(3-4):193-229.

Skapoulli, Elena (2009). Transforming the label of 'whore': Teenage girls' negotiation of local and global gender ideologies in Cyprus. Pragmatics 19(1):85-101.

Sutton, Laurel A. (1995). Bitches and skanky hobags: The place of women in contemporary slang. In Kira Hall \& Mary Bucholtz (eds.), Gender articulated: Language and the socially constructed self, 279-96. London: Routledge.

Tasker, Gillian (ed.) (2000). Social and ethical issues in sexuality education: A resource for health education teachers of year 12 and 13 students. Christchurch: Christchurch College of Education.

Terkourafi, Marina (ed.) (2010). The languages of global Hip Hop. London: Continuum.

Thompson, Katrina Daly (2011). Zanzibari women's discursive and sexual agency: Violating gendered speech prohibitions through talk about supernatural sex. Discourse \& Society 22(1):3-20.

Westinen, Elina (2018). 'Who's afraid of the dark?': The ironic self-stereotype of the ethnic other in Finnish rap music. In Andrew S. Ross \& Damian J. Rivers (eds.), The sociolinguistics of hip-hop as critical conscience: Dissatisfaction and dissent, 131-61. Basingstoke: Palgrave Macmillan.

Williams, Quentin (2015). Emceeing toughness, toughing up the emcee: Language and masculine ideology in freestyle rap performances. In Tommaso, M. Milani (ed.), Language and masculinities: Performances, intersections, dislocations, 77-99. London: Routledge.

(2017). Remix multilingualism: Hip Hop, ethnography and performing marginalized voice. London: Bloomsbury.

Zemke-White, Kirsten (2001). Rap music and Pacific identity in Aotearoa: Popular music and the politics of opposition. In Cluny Macpherson, Paul Spoonley, \& Melani Anae (eds.), Tangata o te moana nui: The evolving identities of Pacific peoples in Aotearoa/New Zealand, 228-42. Palmerston North: Dunmore Press. 
(2005a). 'How many dudes you know roll like this?': The re-presentation of Hip Hop tropes in New Zealand rap music. Image \& Narrative 1(10):1-16.

(2005b). Nesian styles (re)present R'N'B: The appropriation, transformation and realization of contemporary R'N`B with Hip Hop by urban Pasifika groups in Aotearoa. SITES: New Series 2(1):92-123.

Zhang, Qing (2005). A Chinese yuppie in Beijing: Phonological variation and the construction of a new professional identity. Language in Society 34(3):431-66.

(Received 29 January 2017; revision received 23 February 2018; accepted 04 May 2018; final revision received 05 May 2018)

Address for correspondence:

Brian W. King

School of English, University of Hong Kong

Pokfulam, Hong Kong bwking@hku.hk 